\title{
Stigma Experienced by People with Severe Mental Disorders and their Caregivers: A Narrative Review
}

\author{
Melody M Annamalai ${ }^{1}$, Sivaprakash Balasundaram², Sukanto Sarkar ${ }^{3}$, Vigneshvar Chandrasekaran ${ }^{4}$
}

\begin{abstract}
The word 'stigma' means a form of disgrace associated with a particular situation or person. Stigma has a significant detrimental effect on access to mental health care. It is wellknown that people with mental illness and their families experience stigma and discrimination. Studying stigma can aid in planning appropriate anti-stigma programs for patients, family members and for the community. A narrative literature review of research publications on stigma experienced by people with severe mental disorders and their caregivers was conducted by searching PubMed, ProQuest and Google Scholar databases. Both original research and review articles were included. A total of 114 papers were included. All papers presented some information regarding the various aspects of stigma and its impact among persons with mental illness and their caregivers. The level of intensity of stigma among mentally ill individuals and their caregivers ranges from moderate to high, and is greatly influenced by various sociodemographic and illness variables. Research literature implies the need for the alleviation of stigma to improve the overall mental health of the community.

Keywords: Caregiver, Discrimination, Mental illness, Severe mental disorders, Stigma.

Annals of SBV (2019): 10.5005/jp-journals-10085-8109
\end{abstract}

\section{INTRODUCTION}

The World Health Organization (WHO) says that one in four people suffer from mental disorders at some point in their lifetime.' The global burden of severe mental disorders was estimated to be 381 million (depression-300 million, bipolar affective disorder-60 million, and schizophrenia-21 million). ${ }^{2}$ According to the National Mental Health Survey of India "Every sixth person in India needs mental help." ${ }^{3}$ A multicentric study reported that the overall weighted prevalence of mental morbidity in India was $13.7 \%$ and the current mental morbidity is $10.6 \%{ }^{3}$ The WHO estimates that "the burden of mental health problems (in India) is of the tune of 2,443 DALYs per 100,000 population, and the age-adjusted suicide rate is 21.1 per 100,000 population." ${ }^{4}$

A large proportion of people with mental illness do not receive adequate care. ${ }^{5}$ Stigma toward, and discrimination against, people with mental disorders is an important barrier to mental health service utilization in India. It contributes to delay in seeking care; impedes timely diagnosis, treatment, recovery, and rehabilitation; and ultimately reduces the opportunity for fuller participation in life. ${ }^{6}$ Prospective studies provide evidence that stigma may have a negative impact on service use. ${ }^{7}$ Stigma remains the main obstacle to a better life for the many hundreds of millions of people suffering from mental disorders. ${ }^{8}$

The word "stigma" means a form of disgrace associated with a particular situation or person. ${ }^{9}$ Goffmann described stigma as "an attribute that is deeply discrediting" that reduces someone "from a whole and usual person to a tainted, discounted one." Stigmatized individuals are perceived as having a "spoiled identity." ${ }^{10}$ It is wellknown that people with mental illness and their families experience stigma and discrimination. Stigma in relation to mental illness leads others to judge an individual as not having legitimacy to participate in social interaction. ${ }^{11}$ This can lead to social exclusion, low selfesteem, and eventually poor quality of life. Eventually, stigma can lead to discrimination which may be distinct and direct, like making a negative comment about one's illness or treatment, or be subtle,

\begin{abstract}
${ }^{1-4}$ Department of Psychiatry, Mahatma Gandhi Medical College and Research Institute, Puducherry, India

Corresponding Author: Melody M Annamalai, Department of Psychiatry, Mahatma Gandhi Medical College and Research Institute, Puducherry, India, Phone: +91 9791060483, e-mail: dr. melodymichael@gmail.com

How to cite this article: Annamalai MM, Balasundaram S, Sarkar S, Chandrasekaran V. Stigma Experienced by People with Severe Mental Disorders and their Caregivers: A Narrative Review. Ann SBV 2019;8(2):30-37.
\end{abstract}

Source of support: Nil

Conflict of interest: None

such as avoidance of mentally ill individuals, conceiving them to be violent or dangerous. Such experiences of stigmatization can make one judge oneself. ${ }^{12}$

Stigma in relation to patients can be classified as (a) perceived stigma, which is the belief that the public hold negative attitudes toward them, (b) experienced stigma, which is unfair treatment or discrimination due to having a mental illness, and (c) self-stigma, which is a stigmatized view of oneself. ${ }^{13}$

Stigma experienced by caregivers of patients with mental illness is called associative/courtesy/affiliate stigma. Affiliate stigma occurs when the people affiliated with a stigmatized individual such as caregivers (usually family members) are personally affected by public stigma. ${ }^{14}$ Studies suggest that caregiver stigma results in avoidance and frustration toward the patients, self-experiences of depressed mood, emotional burnout, and anxiety. ${ }^{15,16}$ Caregiver stigma has a critical role to play in patient's treatment adherence and recovery. ${ }^{17}$

Though many studies have addressed stigma worldwide, ${ }^{18-24}$ only a few Indian studies have been published to date to the best of the authors' knowledge. ${ }^{14,25}$ Further, studies in Southern India are sparse in comparison to Northern and Central India. ${ }^{26,27}$ 
Also, stigma has been studied individually either on patients or in caregivers, whereas simultaneous evaluation of both groups is scarce. Hence, it is imperative to review the studies about stigma toward individuals with severe mental illness and their caregivers which can aid in planning appropriate antistigma programs for patients, family members, and the community.

\section{Review Methodology}

We aimed to review the research publications on stigma experienced by people with severe mental disorders and their caregivers. PubMed, ProQuest, and Google Scholar databases were searched using the key words "stigma" and "mental illness" and "caregivers of mentally ill." No restriction was set concerning the year of publication. The search strategy initially focused on the presence of these key words in the titles of papers and was expanded to include relevant articles suggested by the database, based on our search. The reference lists of these papers were reviewed to locate more references. Both original research and review articles were included in the study. A total of 129 papers were reviewed by the authors, 14 articles were excluded and finally 115 articles were included. The articles which do not measure stigma associated with mental illness directly and those in languages other than English were excluded.

\section{Stigma and Mental Illness}

The perspectives of people regarding mentally ill patients and the illness per se have been studied in various instances. Following a diagnosis with a psychiatric disorder, a sense of devaluation and a fear of being rejected ensues. ${ }^{28}$ Stigmatization may result from the indiscriminate use of diagnostic labels, which are often misinterpreted by the general population. ${ }^{8}$ Another consistent and major contributor toward stigmatization is the inaccurate portrayal by the media. ${ }^{29}$

Misconceptions regarding mental illnesses have been extensively studied. ${ }^{30}$ In a recent survey conducted in India, regarding public attitudes toward mentally ill individuals, the majority of the respondents said that one should keep a safe distance from those who are depressed. Around 26\% of them reported being afraid. More their awareness about mental health concerns, more was their likelihood of demonstrating stigmatizing attitudes. Only $27 \%$ of the surveyed individuals were supportive of people with mental illnesses-these were young adults, having lower educational levels and from lower socioeconomic backgrounds. The majority of them attributed to a lack of selfdiscipline and willpower as reasons for mental illness, while some believed that mental illness can only happen to people who are "mentally weak." ${ }^{31}$ According to a study by Lauber and Rossler, stigmatizing attitudes among the Asian population are quite common. ${ }^{32}$ An increase in social distancing was directly related to their perception of mentally ill individuals as dangerous. ${ }^{32,33}$ In a German study, majority of the respondents expressed a belief that individuals diagnosed with schizophrenia are often involved in criminal activities and are unpredictable. ${ }^{34}$

Depiction of dangerousness, unpredictability, and criminality among the mentally ill individuals induces negative reactions among people, such as fear, rejection, and ridicule. The consequences are deep, leading to impairment in the domains of self-esteem, helpseeking behaviors, medication adherence, and the overall recovery of patients. ${ }^{29}$ Besides, stigma may induce social awkwardness, demoralization, and unemployment. Link et al. had assessed whether patients can minimize the labeling effects by keeping their treatment history confidential, making others aware of their predicament, or avoiding participation in situations in which rejection is likely to occur. None of these coping strategies were effective in diminishing negative labeling effects and, in fact, did more harm than good. ${ }^{35}$

The stigma associated with mental illness is suggested to be caused by misconceptions among the public which are the products of indiscriminate use of diagnostic labels and incorrect portrayal by the media, leading to detrimental effects on one's self-esteem.

\section{Factors Contributing to the Stigma Associated with Mental Illness}

Multiple factors ranging from physical, emotional, financial, and sociocultural considerably influence the stigma associated with mental illness. In a study by Graves et al., reactions such as increased brow tension and heart rate were observed, while participants were asked to imagine having a conversation with schizophrenia patients. These findings suggest undesirable physiological experiences as a probable reason for avoidance toward people with mental disorders. ${ }^{36}$

Various studies have established that a lack of qualified personnel and financial resources plays a vital role in help-seeking behavior. Most centers are located in urban locations, an inadequate number of psychiatrists, and low funding toward mental health by many low-income countries have been cited as reasons for poor help seeking. ${ }^{31,32,37}$ It is well-known that stigma has a negative impact on help seeking behavior. However, it can be postulated that poor help-seeking may also indirectly contribute to stigma by being associated with a more adverse clinical course.

A few studies have shown lower educational attainment to be associated with higher stigma. ${ }^{26,38}$ A significant number of people believe in the role of supernatural, religious, and magical forces in the causation of mental illness. ${ }^{32}$ Research has suggested stronger religious devotion to be associated with lower levels of stigma. ${ }^{38}$

Higher levels of stigma are observed among people belonging to the higher socioeconomic class and urban regions, with the commonly attributed reason being their concern regarding status and reputation..$^{27,39}$ In contrast, another study reported that rural Indians possess more stigmatizing attitudes, and it is associated with their more authoritarian and socially restrictive views. ${ }^{26}$ Influence of gender on stigma has not been studied extensively, though studies have noted higher stigma among female subjects. Differences in the expected societal and gender roles have been accounted for as the primary reason. ${ }^{27,40}$

\section{Stigma Experienced by Patients with Psychiatric Illness}

Although perspectives about mental illness and socioeconomic factors contribute greatly toward stigma, better understanding and depth of stigmatization comes from the secondary actions, especially on those suffering from mental illness. Stigma experienced by psychiatrically ill patients starts from one's view about self and associating the illness with their identity. A Norwegian study explored the process and state of being reclassified as a stigmatized "other" by psychiatric patients, and its effects on one's self-esteem revealing that isolation, loneliness, 
and the danger of becoming visible as mentally ill as the major consequences. ${ }^{41}$

The participants were inclined toward concealing their disorders and worried about critical treatment from others in a nationwide survey assessing patients' experience of stigma from their families, mental healthcare providers, and at workplace. ${ }^{42}$ Being looked down on people admitted in a psychiatric hospital, reluctance from women to marry and refusal to being friends with a person with mental illness were found in a study by Guttikonda et al., assessing the attitudes of rural population toward people with serious mental disorders. ${ }^{26}$

According to the Mental Health Commission of Canada, discrimination by healthcare professionals serves as a major barrier to quality of care, treatment, and recovery of individuals with mental illness. This includes negativity about a patient's chance of recovery, attribution of unrelated complaints to a patient's mental illness, and refusal to treat psychiatric symptoms in a medical setting. ${ }^{43}$

A study done among the population of Western Australia ${ }^{44}$ presented mentally ill patients to be a stigmatized group with extremely poor health outcomes, who deserve a higher level of care of their physical health compared to the general community. According to the study, they have greater healthcare needs in comparison to the general population, while in reality are receiving less. $^{44}$

Therefore, it is demonstrated from the above studies that stigmatizing experiences of the mentally ill arise from various sources ranging from one's viewpoint to unfair treatment by others, including certain healthcare professionals.

\section{Stigma Experienced by Caregivers of Patients with Psychiatric Illness}

Any illness that affects an individual also affects the close members related to the individual. In cases of psychiatric illness, the impact is however deep-seated extending to aspects such as finance, coping, and psychological status of the caregivers. A study done in New York on caregivers of the mentally ill suggests that stigmatization makes lives tougher for the patients, caregivers, and their families. ${ }^{45} \mathrm{An}$ Ethiopian study revealed the majority of caregivers are experiencing stigma because of mental illness in the family. ${ }^{46}$ According to a study by Trani et al., negative attitudes about mental illness are reflected in the denial of employment, leading to an increase in the financial burden of the family. ${ }^{47}$ A study by Zhang et al. established affiliate stigma among caregivers having notable associations with quality of life. ${ }^{48}$ Similarly, a study in Jordan revealed that the perceived quality of life among caregivers was low to moderate as assessed by the self-administered questionnaires. ${ }^{49} \mathrm{~A}$ review article by Greenwood et al. discussed the role of social exclusion as an important part of discrimination toward caregivers. ${ }^{50}$ Stigma was found to have negative effects on the levels of empowerment and functioning, serving as a source of distress for families with mentally ill individuals. ${ }^{51}$

Lower educational levels, being divorced/separated, and unemployment of caregivers were linked with low quality of life. ${ }^{52}$ Few other studies have also established similar findings of gender, marital status, and area of domicile having paramount associations with higher levels of caregiver stigma by using validated scales and structured interviews. ${ }^{53,54}$ In a study published by Ergetie et al., higher perceived stigma among caregivers was associated with factors such as the female gender, rural area of domicile, poor societal support, and longer duration of the relationship with the patient. ${ }^{55}$ Greater levels of caregiver's insight about illness are shown to be associated with higher stigma levels. ${ }^{24} \mathrm{~A}$ meta-analysis published by Shi et al. had suggested attribution of the disease, amount of time spent in caregiving per day, and the psychosocial variables such as face concern, stress, and support from others as significant factors associated with affiliate stigma. ${ }^{56}$

Blaming parents of the individuals, accusing them of being irresponsible and caring less for the mentally ill and having a tendency to look down on families with mentally ill individuals are the common attitudes among the public. ${ }^{26,57}$ The majority of caregivers had worries over being treated differently and therefore wanted to hide the fact of having a mentally ill person in the family. ${ }^{46}$ Parents of people with mental illness reported more stigma and expressed difficulties in making other people understand their burden as a caregiver. ${ }^{48}$ Dadson et al. had investigated the experiences and coping strategies of psychiatric nurses and family caregivers. ${ }^{58}$ Regarding the stigmatizing experiences, the family members experienced it from the public, especially their neighbors, whereas the psychiatric nurses experienced it from their fellow health workers. While psychiatric nurses adopted humor as a coping strategy, family members resorted to emotion-focused coping strategies. ${ }^{58}$ Psychological problems such as depression, anxiety, and suicidal thoughts among caregivers of people with mental disorders have been demonstrated by various studies. ${ }^{15,52,59}$

Multiple factors including poor knowledge about mental illness, supernatural beliefs about mental illness, chronicity, financial difficulties, and inadequate mental health services contribute toward caregiver stigma. ${ }^{17,60-62}$ Society's negative attitude toward families of people with mental illness and self-stigma in these individuals lead to social isolation and increased psychological morbidity among caregivers. ${ }^{15,51}$ Such stigmatizing experiences could lead to adverse effects on quality of life. ${ }^{48,52}$

\section{Stigma among Patients with SCHIZOPHRENIA}

Any mental illness has a profound impact on various domains of life of an individual. This holds greater critical value, specifically in cases of persons suffering from psychotic illnesses such as schizophrenia. Many studies have established higher levels of stigma associated with lower levels of functioning in patients with schizophrenia, as assessed by standard and validated scales for assessing illness severity and mental illness stigma. ${ }^{63,64}$ A study by Lysaker et al. found positive correlations between the positive symptoms of schizophrenia and the level of social functioning. ${ }^{65}$ Higher stigma levels during follow-up were associated with the initial level of positive symptoms. ${ }^{65}$ Patients with schizophrenia cited symptoms such as hallucinations, delusions, and suspiciousness as one of the main reasons for their discrimination in family and workplace. ${ }^{66,67}$

The influence of insight on stigma has been studied and concluded that insight modulates stigma. ${ }^{68-71}$ These studies have shown that good insight could have negative effects like increased self-stigma, low self-esteem, secondary depressed mood, and poor quality of life. In contradiction to this, Singh et al. published a study stating that better knowledge about the condition is linked with lower stigma levels. ${ }^{64} \mathrm{~A}$ study in Switzerland stated that insight can result in negative outcomes when the stereotyping experiences are internalized by the individuals. ${ }^{72}$ Higher levels of self-stigma among patients with schizophrenia were linked with levels of empowerment and social contact. ${ }^{18}$ Chronic nature of the illness affects perceived stigma of patients in the form of loss of positive 
societal participation and identity. ${ }^{73}$ Thus, the associations between symptomatology and stigma among patients with schizophrenia is well established by these studies

\section{Stigma among Patients with Bipolar Disorder}

Studies suggest that the level of stigmatization among patients with bipolar disorder is higher when compared to people with depressive disorders and lower than those diagnosed with schizophrenia. ${ }^{74-76}$ Nevertheless, it cannot be ignored and the associated effects in such individuals and their caregivers require attention. A study done in Denmark using validated self-rated scales revealed patients' levels of self-compassion to be seriously low and associated with their overall satisfaction about life. ${ }^{77}$ A study in New York reported levels of internalized stigma having a significant association with the patient's internalizing personality traits. ${ }^{78}$ The fear of rejection is seen to be affecting close personal relationships and in forwardness to seek treatment among patients with bipolar disorder. ${ }^{79}$ In terms of close and professional relationships, the stigmatization might be exhibited in the form of distancing. A strong association with stigma levels and fear of relationships has been demonstrated by another study. ${ }^{80}$

Studies have demonstrated significant negative correlations between stigma and the employment status among patients with bipolar disorder. ${ }^{75,81}$ Stigmatizing views of the public about hospitalization in a psychiatric care facility is also a critical factor. ${ }^{82}$ Increased levels of expressed emotions among caregivers contribute toward self-devaluation and stigma in patients with bipolar disorder. ${ }^{83}$ The subsyndromal depressive symptoms during the interepisodic period cause severe functional decline, contributing toward burden and stigma. ${ }^{81,83}$ The level of insight also has an adverse impact on patients' hopes of improvement and selfworth. ${ }^{79}$ Self-stigma among patients with bipolar disorder serves as a major barrier to treatment adherence, better health outcomes, and recovery rates. ${ }^{74,75,81}$ These articles suggest that vital areas of the normal functioning of these individuals are affected by both self-stigma and experienced stigma.

\section{Stigma among Patients with Depressive DISORDER}

The most stigmatizing view regarding depression is that it is often equated as a sign of weakness, failing to acknowledge the illness or concealment especially in the American African population who tend to have more depression severity as compared to the Caucasian population. ${ }^{84}$ The relation between stigma and the presentation of somatic symptoms has been established by various studies. ${ }^{84-87}$ One of the possible reasons could be depressive symptoms being considered as "socially disadvantageous" by the cultural influences, especially among the Asian population. ${ }^{32,86}$ India's patriarchal society has imbibed the idea in its population that "it's not OK to not be OK," forcing individuals to resort to concealment of their depression and act normal. ${ }^{88}$ However, the overall level of public stigma is relatively lower for depressive disorders, as revealed in a study done in the Middle East. ${ }^{89}$

Personality features such as higher levels of psychoticism and interpersonal sensitivity are exhibited by persons with depressive disorder. ${ }^{21}$ Neuroticism was mainly linked to stigma aspects such as secrecy, while extroversion showed strong correlations with perceived, public, and self-stigma. ${ }^{90}$ Most people resort to hiding their illness and treatment status to others, owing to the fear of being shunned. ${ }^{91}$ Self-stigmatizing views of patients account for the low quality of life ${ }^{92,93}$ and poor treatment adherence as demonstrated by the application of validated instruments in these individuals. $^{94}$

Studies have suggested a lack of social support as a contributor to stigma in depressive disorder patients, ${ }^{21}$ while some believe it to be the cause of depression. ${ }^{95}$ Female gender and married individuals have more discriminating experiences. ${ }^{91,96}$ Both anticipated and experienced discrimination is higher in terms of employment and relationships, while experienced discrimination is higher in persons with a history of hospitalization. ${ }^{91}$ Severity of the illness is associated with increased stigma levels, ${ }^{85,97}$ while insight about the illness has no association with stigma/quality of life of patients with depressive disorder. ${ }^{93}$

The above literature review elucidates that stigma among people with a depressive illness results mainly from the sociocultural influences and personality traits of the individuals themselves. Suffering from severe mental disorders often results in a cumulative adverse impact on the lives of the individuals owing to the stigmatization and the illness per se.

\section{Need for Assessing Stigma}

Stigma as a risk factor has extensive impacts on the patient's treatment process and recovery. Stigma also increases the risk of relapse which in turn can lead to dreadful events such as suicide, violence, and harm to others. ${ }^{98}$ The root cause is the lack of knowledge and awareness about the aspects of mental health and treatment options. ${ }^{33,99}$ Strong correlation between mental health literacy and low stigma levels has been shown by various studies. ${ }^{100,101}$ Prior contact with mentally ill patients has also shown to improve the acceptance level among people. ${ }^{102,103}$

Certain researchers have suggested the need for assessment of stigma as part of the routine clinical examination. Recognition of the aspects of the stigma that are linked with the course of help seeking is also crucial. A Norwegian study indicates that healthcare professionals should be aware of stigma while conceptualizing the services and care for patients with psychiatric illness. ${ }^{41}$ Assessing the cultural aspects and the attitudes and involvement of the family members which are considered to be additive to the selfstigma of patients are vital. ${ }^{104}$ Studies suggest that identification of changeable social factors, assessment of patient's stigmatizing views during the episodes, and spotting barriers to care can aid in improving the quality of care. ${ }^{98,100,105}$

\section{Need for Implementing Antistigma Measures}

The WHO about Mental Health in India has stated that "Interventions, focusing on raising awareness of mental health issues and mobilizing efforts in support of mental health, are necessary for addressing the situation."4

People with mental illness insist on public education as the channel for reducing stigma. ${ }^{42}$ Antistigma programs by various international organizations have used strategies such as social contact, education of the public, and protests to combat stigma. ${ }^{106-109}$ Encouraging patients to discuss their stigmatizing experiences is another way to deal with stigma. ${ }^{107,110}$ Such interventions can be employed in workplace settings to improve supportive behavior. ${ }^{111}$ 
Specific educational programs need to be implemented to reduce the public stigma toward the caregivers. ${ }^{48,58}$ Involvement of caregivers in antistigma initiatives has been suggested as one of the best practices to fight stigma. ${ }^{112}$ Providing counseling services and psychoeducation about managing stigmatizing experiences and adopting healthier coping strategies are the proposed methods to combat caregiver stigma.

Many review articles have revealed observable changes in the attitudes of people and an increase in their knowledge, following antistigma programs. However, the benefits seem short-term and their lasting impact is often questionable. Some group-level antistigma measures have shown to have a positive impact. ${ }^{106,113}$ The interventions to reduce self-stigma in mentally ill individuals are minimal and their impact is less persuasive. ${ }^{114,115}$ Hence, it is indicative that antistigma measures are indispensable in the road toward better mental health.

\section{CONCLUSION}

Individuals suffering from severe mental disorders and their caregivers experience a cumulative adverse impact on their lives owing to stigmatization apart from the illness per se. Both sociodemographic and clinical variables contribute significantly to stigma. Stigma has consequential effects on the sociooccupational functioning, financial status, and quality of life in both patients and their caregivers. Stigma and its correlates contribute significantly toward mental health burden and hence there is a need for the alleviation of stigma to improve the overall mental health of the community.

\section{References}

1. WHO|Mental disorders affect one in four people [Internet]. WHO. [cited 2017 Nov 5]. Available from: http://www.who.int/whr/2001/ media_centre/press_release/en/.

2. World Health Organisation. WHO|10 facts on mental health [Internet]. [cited 2017 Oct 10]. Available from: http://www.who.int/features/ factfiles/mental_health/mental_health_facts/en/index5.html.

3. Murthy RS. National mental health survey of India 2015-2016. Indian J Psychiatry 2017;59(1):21-26. DOI: 10.4103/psychiatry. IndianJPsychiatry_102_17.

4. World Health Organization, Mental health in India [Internet]. SEARO. [cited 2019 Oct 9]. Available from: http://www.searo.who.int/india/ topics/mental_health/about_mentalhealth/en/.

5. Thornicroft G. Most people with mental illness are not treated. Lancet 2007;370(9590):807-808. DOI: 10.1016/S0140-6736(07)61392-0.

6. Shidhaye R, Kermode M. Stigma and discrimination as a barrier to mental health service utilization in India. Int Health 2013;5(1):6-8. DOI: 10.1093/inthealth/ihs011.

7. Clement S, Brohan E, Jeffery D, Henderson C, Hatch SL, Thornicroft G. Development and psychometric properties the barriers to access to care evaluation scale (BACE) related to people with mental ill health. BMC Psychiatry 2012;12:36. DOI: 10.1186/1471-244X-12-36.

8. Sartorius N. latrogenic stigma of mental illness. BMJ 2002;324(7352):1470-1471. DOI: 10.1136/bmj.324.7352.1470.

9. Stigma|Definition of stigma in English by Oxford Dictionaries [Internet]. Oxford Dictionaries|English. [cited 2017 Nov 4]. Available from: https://en.oxforddictionaries.com/definition/stigma.

10. Goffmann E. Stigma: Notes on the management of spoiled identity. New York: Simon and Schuster; 1963.

11. Elliott GC, Ziegler HL, Altman BM, Scott DR. Understanding stigma: dimensions of deviance and coping. Deviant Behav 1982;3(3): 275-300. DOI: 10.1080/01639625.1982.9967590.

12. Mental health: Overcoming the stigma of mental illness [Internet]. Mayo Clinic. [cited 2019 Oct 9]. Available from: https://www. mayoclinic.org/diseases-conditions/mental-illness/in-depth/mentalhealth/art-20046477.

13. Brohan E, Clement S, Rose D, Sartorius N, Slade M, Thornicroft G. Development and psychometric evaluation of the Discrimination and Stigma Scale (DISC). Psychiatry Res 2013;208(1):33-40. DOI: 10.1016/ j.psychres.2013.03.007.

14. Singh A, Mattoo S, Grover S. Stigma associated with mental illness: conceptual issues and focus on stigma perceived by the patients with schizophrenia and their caregivers. Indian J Soc Psychiatry Mumbai 2016;32(2):134-142. Available from: https://search.proquest.com/ health/docview/1824351149/abstract/FDBD0E95FD234FCOPQ/1.

15. Grover S, Avasthi A, Singh A, Dan A, Neogi R, Kaur D, et al. Stigma experienced by caregivers of patients with severe mental disorders: a nationwide multicentric study. Int J Soc Psychiatry 2017;63(5):407-417. DOI: $10.1177 / 0020764017709484$.

16. Steele A, Maruyama N, Galynker I. Psychiatric symptoms in caregivers of patients with bipolar disorder: a review. J Affect Disord 2010;121(1-2): 10-21. DOI: 10.1016/j.jad.2009.04.020.

17. Girma E, Möller-Leimkühler AM, Dehning S, Mueller N, Tesfaye M, Froeschl G. Self-stigma among caregivers of people with mental illness: toward caregivers' empowerment. J Multidiscip Healthc 2014;7:37-43. DOI: 10.2147/JMDH.S57259.

18. Brohan E, Elgie R, Sartorius N, Thornicroft G. Self-stigma, empowerment and perceived discrimination among people with schizophrenia in 14 European countries: the GAMIANEurope study. Schizophr Res 2010;122(1-3):232-238. DOI: 10.1016/ j.schres.2010.02.1065.

19. Vrbova K, Prasko J, Holubova M, Kamaradova D, Ociskova M Marackova M, et al. Self-stigma and schizophrenia: a cross-sectional study. Neuropsychiatr Dis Treat 2016;12:3011-3020. DOI: 10.2147/NDT. S120298.

20. Thornicroft G, Rose D, Kassam A, Sartorius N. Stigma: ignorance, prejudice or discrimination? Br J Psychiatry 2007;190(3):192-193. DOI: 10.1192/bjp.bp.106.025791.

21. Sun Y, Chen G, Wang L, Li N, Srisurapanont M, Hong JP, et al. Perception of Stigma and its associated factors among patients with major depressive disorder: a multicenter survey from an Asian population. Front Psychiatry 2019;10:321. DOI: 10.3389/fpsyt.2019.00321.

22. Chang C-C, Yen C-F, Jang F-L, Su J-A, Lin C-Y. Comparing affiliate stigma between family caregivers of people with different severe mental illness in Taiwan. J Nerv Ment Dis 2017;205(7):542-549. DOI: 10.1097/NMD.0000000000000671.

23. Lazowski L, Koller M, Stuart H, Milev R. Stigma and discrimination in people suffering with a mood disorder: a cross-sectional study. Depress Res Treat 2012;2012:724848. DOI: 10.1155/2012/724848.

24. Hasson-Ohayon I, Levy I, Kravetz S, Vollanski-Narkis A, Roe D. Insight into mental illness, self-stigma, and the family burden of parents of persons with a severe mental illness. Compr Psychiatry 2011;52(1): 75-80. DOI: 10.1016/j.comppsych.2010.04.008.

25. Grover S, Avasthi A, Singh A, Dan A, Neogi R, Kaur D, et al. Stigma experienced by patients with severe mental disorders: a nationwide multicentric study from India. Psychiatry Res 2017;257:550-558. DOI: 10.1016/j.psychres.2017.08.027.

26. Guttikonda A, Shajan AM, Hephzibah A, Jones AS, Susanna J, Neethu $S$, et al. Perceived Stigma regarding mental illnesses among rural adults in Vellore, Tamil Nadu, South India. Indian J Psychol Med 2019;41(2):173-177. DOI: 10.4103/IJPSYM.IJPSYM_297_18.

27. Venkatesh BT, Andrews T, Mayya SS, Singh MM, Parsekar SS. Perception of stigma toward mental illness in South India. J Fam Med Prim Care 2015;4(3):449-453. DOI: 10.4103/2249-4863.161352.

28. Link BG. Understanding labeling effects in the area of mental disorders: an assessment of the effects of expectations of rejection. Am Sociol Rev 1987;52(1):96-112. DOI: 10.2307/2095395.

29. Stuart H. Media portrayal of mental illness and its treatments: what effect does it have on people with mental illness? CNS Drugs 2006;20(2):99-106. DOI: 10.2165/00023210-200620020-00002.

30. Corrigan PW, Watson AC. Understanding the impact of stigma on people with mental illness. World Psychiatry 2002;1(1):16-20. 
31. Thomas M, . Charted: India's shocking attitudes towards mental illness [Internet]. Quartz India. [cited 2019 Oct 7]. Available from: https:// qz.com/india/1237314/fear-and-apathy-how-indians-look-at-thosesuffering-mental-illnesses/.

32. Lauber C, Rössler W. Stigma towards people with mental illness in developing countries in Asia. Int Rev Psychiatry 2007;19(2):157-178. DOI: 10.1080/09540260701278903.

33. Prabhu GG, Verma ARN, Maridass AC. Public attitudes toward mental illness: a review. NIMHANS J 1984;2(1):1-14.

34. Angermeyer MC, Matschinger $\mathrm{H}$. The stereotype of schizophrenia and its impact on discrimination against people with schizophrenia: results from a representative survey in Germany. Schizophr Bull 2004;30(4):1049-1061. DOI: 10.1093/oxfordjournals.schbul. a007120.

35. Link BG, Mirotznik J, Cullen FT. The effectiveness of stigma coping orientations: can negative consequences of mental illness labeling be avoided? J Health Soc Behav 1991;32(3):302-320. DOI: $10.2307 / 2136810$

36. Graves RE, Cassisi JE, Penn DL. Psychophysiological evaluation of stigma towards schizophrenia. Schizophr Res 2005;76(2-3):317-327. DOI: 10.1016/j.schres.2005.02.003.

37. Saxena S, Thornicroft G, Knapp M, Whiteford H. Resources for mental health: scarcity, inequity, and inefficiency. Lancet 2007;370(9590):878-889. DOI: 10.1016/S0140-6736(07)61239-2.

38. Zieger A, Mungee A, Schomerus G, Ta TMT, Dettling M, Angermeyer $M C$, et al. Perceived stigma of mental illness: a comparison between two metropolitan cities in India. Indian J Psychiatry 2016;58(4): 432-437. DOI: 10.4103/0019-5545.196706.

39. Barke A, Nyarko S, Klecha D. The stigma of mental illness in Southern Ghana: attitudes of the urban population and patients' views. Soc Psychiatry Psychiatr Epidemiol 2011;46(11):1191-1202. DOI: 10.1007/ s00127-010-0290-3.

40. Boge K, Zieger A, Mungee A, Tandon A, Fuchs LM, Schomerus G, et al. Perceived stigmatization and discrimination of people with mental illness: a survey-based study of the general population in five metropolitan cities in India. Indian J Psychiatry 2018;60(1):24-31. DOI: 10.4103/psychiatry.IndianJPsychiatry_406_17.

41. Thesen J. Being a psychiatric patient in the community--reclassified as the stigmatized "other". Scand J Public Health 2001;29(4):248-255. DOI: $10.1177 / 14034948010290040901$.

42. Wahl OF. Mental health consumers' experience of stigma. Schizophr Bull 1999;25(3):467-478. DOI: 10.1093/oxfordjournals.schbul.a033394.

43. Pellegrini C. Mental illness stigma in health care settings a barrier to care. CMAJ Can Med Assoc J 2014;186(1):E17. DOI: 10.1503/cmaj.1094668.

44. Lawrence D, Coghlan R. Health inequalities and the health needs of people with mental illness. New South Wales Public Health Bull 2002;13(7):155. DOI: 10.1071/NB02063.

45. Struening EL, Perlick DA, Link BG, Hellman F, Herman D, Sirey JA. Stigma as a barrier to recovery: the extent to which caregivers believe most people devalue consumers and their families. Psychiatr Serv 2001;52(12):1633-1638. DOI: 10.1176/appi.ps.52.12.1633.

46. Shibre T, Negash A, Kullgren G, Kebede D, Alem A, Fekadu A, et al. Perception of stigma among family members of individuals with schizophrenia and major affective disorders in rural Ethiopia. Soc Psychiatry Psychiatr Epidemiol 2001;36(6):299-303. DOI: 10.1007/ s001270170048.

47. Trani J-F, Bakhshi P, Kuhlberg J, Narayanan SS, Venkataraman H, Mishra $\mathrm{NN}$, et al. Mental illness, poverty and stigma in India: a case-control study. BMJ Open 2015;5(2):e006355. DOI: 10.1136/bmjopen-2014006355.

48. Zhang $Y$, Subramaniam $M$, Lee $S P$, Abdin $E$, Sagayadevan $V$, Jeyagurunathan $A$, et al. Affiliate stigma and its association with quality of life among caregivers of relatives with mental illness in Singapore. Psychiatry Res 2018;265:55-61. DOI: 10.1016/ j.psychres.2018.04.044.

49. Dalky HF, Qandil AM, Natour AS, Janet MC. Quality of life, stigma and burden perception among family caregivers and patients with psychiatric illnesses in Jordan. Community Ment Health J 2017;53(3):266-274. DOI: 10.1007/s10597-016-0028-0.

50. Greenwood N, Mezey G, Smith R. Social exclusion in adult informal carers: a systematic narrative review of the experiences of informal carers of people with dementia and mental illness. Maturitas 2018;112:39-45. DOI: 10.1016/j.maturitas.2018.03.011.

51. Muralidharan A, Lucksted A, Medoff D, Fang LJ, Dixon L. Stigma: a unique source of distress for family members of individuals with mental illness. J Behav Health Serv Res 2016;43(3):484-493. DOI: 10.1007/s11414-014-9437-4.

52. Jeyagurunathan A, Sagayadevan V, Abdin E, Zhang Y, Chang S, Shafie $S$, et al. Psychological status and quality of life among primary caregivers of individuals with mental illness: a hospital based study. Health Qual Life Outcomes 2017;15(1):106. DOI: 10.1186/s12955-0170676-y.

53. Mukherjee S, Mukhopadhyay DK. Stigma towards mental illness: a hospital-based cross-sectional study among caregivers in West Bengal. Indian J Public Health 2018;62(1):15-20. DOI: 10.4103/ijph. IJPH_88_17.

54. Neupane D, Dhakal S, Thapa S, Bhandari PM, Mishra SR. Caregivers' attitude towards people with mental illness and perceived stigma: a cross-sectional study in a tertiary hospital in Nepal. PloS One 2016;11(6):e0158113. DOI: 10.1371/journal.pone.0158113.

55. Ergetie T, Yohanes Z, Asrat B, Demeke W, Abate A, Tareke M. Perceived stigma among non-professional caregivers of people with severe mental illness, Bahir Dar, northwest Ethiopia. Ann Gen Psychiatry 2018;17:42. DOI: 10.1186/s12991-018-0212-4.

56. Shi Y, Shao Y, Li H, Wang S, Ying J, Zhang M, et al. Correlates of affiliate stigma among family caregivers of people with mental illness: a systematic review and meta-analysis. J Psychiatr Ment Health Nurs 2019;26(1-2):49-61. DOI: 10.1111/jpm.12505.

57. Pawar AA, Peters A, Rathod J. Stigma of mental illness: Aa study in the Indian Armed Forces. Med J Armed Forces India 2014;70(4):354-359. DOI: 10.1016/j.mjafi.2013.07.008.

58. Dadson DA, Annor F, Salifu Yendork J. The burden of care: psychosocial experiences and coping strategies among caregivers of persons with mental illness in Ghana. Issues Ment Health Nurs 2018;39(11):915-923. DOI: $10.1080 / 01612840.2018 .1496208$.

59. Östman M, Kjellin L. Stigma by association: psychological factors in relatives of people with mental illness. Br J Psychiatry 2002;181(6):494-498. DOI: 10.1192/bjp.181.6.494.

60. Poreddi V, Blrudu R, Thimmaiah R, Math SB. Mental health literacy among caregivers of persons with mental illness: a descriptive survey. J Neurosci Rural Pract 2015;6(3):355-360. DOI: 10.4103/09763147.154571

61. Tsang HWH, Tam PKC, Chan F, Cheung WM, Chang WM. Sources of burdens on families of individuals with mental illness. Int J Rehabil Res 2003;26(2):123-130. DOI: 10.1097/01.mrr.0000070761.13531.a1.

62. Chadda RK. Caring for the family caregivers of persons with mental illness. Indian J Psychiatry 2014;56(3):221-227. DOI: 10.4103/00195545.140616.

63. Yanos PT, Lysaker PH, Roe D. Internalized stigma as a barrier to improvement in vocational functioning among people with schizophrenia-spectrum disorders. Psychiatry Res 2010;178(1): 211-213. DOI: 10.1016/j.psychres.2010.01.003.

64. Singh A, Mattoo SK, Grover S. Stigma and its correlates in patients with schizophrenia attending a general hospital psychiatric unit. Indian J Psychiatry 2016;58(3):291-300. DOI: 10.4103/0019-5545.192024.

65. Lysaker PH, Davis LW, Warman DM, Strasburger A, Beattie N. Stigma, social function and symptoms in schizophrenia and schizoaffective disorder: associations across 6 months. Psychiatry Res 2007;149(1-3): 89-95. DOI: 10.1016/j.psychres.2006.03.007.

66. Shrivastava A, Johnston ME, Thakar M, Shrivastava S, Sarkhel G, Sunita I, et al. Impact and origin of stigma and discrimination in schizophrenia: patient perceptions. Stigma Res Action 2011;1(1):67-72. DOI: 10.5463/sra.v1i1.5.

67. Bifftu BB, Dachew BA. Perceived Stigma and associated factors among people with schizophrenia at Amanuel mental specialized hospital, 
Addis Ababa, Ethiopia: a cross-sectional institution based study. Psychiatry J 2014;2014:694565. DOI: 10.1155/2014/694565.

68. Lien Y-J, Chang H-A, Kao Y-C, Tzeng N-S, Lu C-W, Loh C-H. Insight, self-stigma and psychosocial outcomes in Schizophrenia: a structural equation modelling approach. Epidemiol Psychiatr Sci 2018;27(2): 176-185. DOI: 10.1017/S2045796016000950.

69. Staring $A B P$, Van der Gaag $M$, Van den Berge $M$, Duivenvoorden $\mathrm{HJ}$, Mulder CL. Stigma moderates the associations of insight with depressed mood, low self-esteem, and low quality of life in patients with schizophrenia spectrum disorders. Schizophr Res 2009;115(2-3): 363-369. DOI: 10.1016/j.schres.2009.06.015.

70. Mishra DK, Alreja S, Sengar KS, Singh AR. Insight and its relationship with stigma in psychiatric patients. Ind Psychiatry J 2009;18(1):39-42. DOI: 10.4103/0972-6748.57858.

71. Hasson-Ohayon I, Kravetz S, Roe D, David AS, Weiser M. Insight into psychosis and quality of life. Compr Psychiatry 2006;47(4):265-269. DOI: 10.1016/j.comppsych.2005.08.006.

72. Cavelti M, Kvrgic S, Beck E-M, Rüsch N, Vauth R. Self-stigma and its relationship with insight, demoralization, and clinical outcome among people with schizophrenia spectrum disorders. Compr Psychiatry 2012;53(5):468-479. DOI: 10.1016/j.comppsych.2011.08.001.

73. Estroff SE. Self, identity, and subjective experiences of schizophrenia: in search of the subject. Schizophr Bull 1989;15(2):189-196. DOI: 10.1093/schbul/15.2.189.

74. Latalova K, Ociskova M, Prasko J, Kamaradova D, Jelenova D, Sedlackova Z. Self-stigmatization in patients with bipolar disorder. Neuro Endocrinol Lett 2013;34(4):265-272.

75. Pal A, Sharan P, Chadda RK. Internalized stigma and its impact in Indian outpatients with bipolar disorder. Psychiatry Res 2017;258: 158-165. DOI: 10.1016/j.psychres.2017.09.087.

76. Ouanes S, Mrizak J, Arouss A, Ben Hammouda A, Rafrafi R, El Hechmi Z. Impact of Stigma on euthymic patients with bipolar disorder type I. Abstr 23rd Eur Congr Psychiatry 2015;30(Suppl 1):562. DOI: 10.1016/ S0924-9338(15)30445-4.

77. Døssing M, Nilsson KK, Svejstrup SR, Sørensen VV, Straarup KN, Hansen TB. Low self-compassion in patients with bipolar disorder. Compr Psychiatry 2015;60:53-58. DOI: 10.1016/j.comppsych.2015.03.010.

78. Bassirnia A, Briggs J, Kopeykina I, Mednick A, Yaseen Z, Galynker I. Relationship between personality traits and perceived internalized stigma in bipolar patients and their treatment partners. Psychiatry Res 2015;230(2):436-440. DOI: 10.1016/j.psychres.2015.09.033.

79. Hajda M, Prasko J, Latalova K, Hruby R, Ociskova M, Holubova M, et al. Unmet needs of bipolar disorder patients. Neuropsychiatr Dis Treat 2016;12:1561-1570. DOI: 10.2147/NDT.S105728.

80. Sarısoy G, Kaçar ÖF, Pazvantoğlu O, Korkmaz IZ, Öztürk A, Akkaya $D$, et al. Internalized stigma and intimate relations in bipolar and schizophrenic patients: a comparative study. Compr Psychiatry 2013;54(6):665-672. DOI: 10.1016/j.comppsych.2013.02.002.

81. Grover S, Hazari N, Aneja J, Chakrabarti S, Sharma S, Avasthi A. Recovery and its correlates among patients with bipolar disorder: a study from a tertiary care centre in North India. Int J Soc Psychiatry 2016;62(8):726-736. DOI: 10.1177/0020764016676214.

82. Nilsson KK, Kugathasan P, Straarup KN. Characteristics, correlates and outcomes of perceived stigmatization in bipolar disorder patients. J Affect Disord 2016;194:196-201. DOI: 10.1016/j.jad.2016.01.025.

83. Ogilvie AD, Morant N, Goodwin GM. The burden on informal caregivers of people with bipolar disorder. Bipolar Disord 2005;7(Suppl 1):25-32. DOI: 10.1111/j.1399-5618.2005.00191.x.

84. Bailey RK, Blackmon HL, Stevens FL. Major depressive disorder in the African American population: meeting the challenges of stigma, misdiagnosis, and treatment disparities. J Natl Med Assoc 2009;101(11):1084-1089. DOI: 10.1016/S0027-9684(15)31102-0.

85. Shi-Jie F, Hong-Mei G, Li W, Bin-Hong W, Yi-Ru F, Gang W, et al. Perceptions of stigma and its correlates among patients with major depressive disorder: a multicenter survey from China. Asia Pac Psychiatry 2017;9(3). DOI: 10.1111/appy.12260.

86. Raguram R, Weiss MG, Channabasavanna SM, Devins GM. Stigma, depression, and somatization in South India. Am J Psychiatry 1996;153(8):1043-1049. DOI: 10.1176/ajp.153.8.1043.
87. Chowdhury AN, Sanyal D, Bhattacharya A, Dutta SK, De R, Banerjee S, et al. Prominence of symptoms and level of stigma among depressed patients in Calcutta. J Indian Med Assoc 2001;99(1):20-23.

88. Dandona R, Kumar GA, Dhaliwal RS, Naghavi M, Vos T, Shukla DK, et al. Gender differentials and state variations in suicide deaths in India: the Global Burden of Disease Study 1990-2016. Lancet Public Health 2018;3(10):e478-e489. DOI: 10.1016/S2468-2667(18)30138-5.

89. Sewilam AM, Watson AMM, Kassem AM, Clifton S, McDonald MC, Lipski $R$, et al. Suggested avenues to reduce the stigma of mental illness in the Middle East. Int J Soc Psychiatry 2015;61(2):111-120. DOI: 10.1177/0020764014537234.

90. Borecki L, Gozdzik-Zelazny A, Pokorski M. Personality and perception of stigma in psychiatric patients with depressive disorders. Eur J Med Res 2010;15(Suppl 2):10-16. DOI: 10.1186/2047-783X-15-S2-10.

91. Milačić Vidojević I, Dragojević N, Tošković O. Experienced and anticipated discrimination among people with major depressive disorder in Serbia. Int J Soc Psychiatry 2015;61(7):638-644. DOI: 10.1177/0020764014568325.

92. Holubova M, Prasko J, Ociskova M, Marackova M, Grambal A, Slepecky M. Self-stigma and quality of life in patients with depressive disorder: a cross-sectional study. Neuropsychiatr Dis Treat 2016;12:2677-2687. DOI: 10.2147/NDT.S118593.

93. Yen C-F, Chen C-C, Lee Y, Tang T-C, Ko C-H, Yen J-Y. Association between quality of life and self-stigma, insight, and adverse effects of medication in patients with depressive disorders. Depress Anxiety 2009;26(11):1033-1039. DOI: 10.1002/da.20413.

94. Sedlácková Z, Kamarádová D, Prásko J, Látalová K, Ocisková M, Ocisková $\mathrm{M}$, et al. Treatment adherence and self-stigma in patients with depressive disorder in remission - a cross-sectional study. Neuro Endocrinol Lett 2015;36(2):171-177.

95. Koller R, Haslacher $\mathrm{H}$, Kienesberger $\mathrm{K}$, Schmöger $\mathrm{M}$, Schosser A. Attitudes towards anti-depressive therapy: acceptance vs stigmatization. Neuropsychiatr 2015;29(1):14-22. DOI: 10.1007/s40211014-0134-6.

96. Khan N, Kausar R, Khalid A, Farooq A. Gender differences among discrimination \& stigma experienced by depressive patients in Pakistan. Pak J Med Sci 2015;31(6):1432-1436. DOI: 10.12669/ pjms.316.8454.

97. Gaudiano BA, Miller IW. Self-stigma and attitudes about treatment in depressed patients in a hospital setting. Int J Soc Psychiatry 2013;59(6):586-591. DOI: 10.1177/0020764012446404.

98. Shrivastava A, Bureau Y, Rewari N, Johnston M. Clinical risk of stigma and discrimination of mental illnesses: need for objective assessment and quantification. Indian J Psychiatry 2013;55(2):178-182. DOI: 10.4103/0019-5545.111459.

99. Somasundaram O. Literary destigmatisation of mental illness: a study of the writings of Jayakanthan. Indian J Psychiatry 2013;55(3):295-299. DOI: 10.4103/0019-5545.117154.

100. Wong EC, Collins RL, Breslau J, Burnam MA, Cefalu M, Roth EA. Differential association of stigma with perceived need and mental health service use. J Nerv Ment Dis 2018;206(6):461-468. DOI: 10.1097/ NMD. 0000000000000831.

101. Svensson B, Hansson L. How mental health literacy and experience of mental illness relate to stigmatizing attitudes and social distance towards people with depression or psychosis: a crosssectional study. Nord J Psychiatry 2016;70(4):309-313. DOI: 10.3109/08039488.2015.1109140.

102. Alamri Y. Mental illness in Saudi Arabia: stigma and acceptability. Int J Soc Psychiatry 2016;62(3):306-307. DOI: 10.1177/002076401 6628896.

103. Adewuya AO, Makanjuola ROA. Social distance towards people with mental illness in southwestern Nigeria. Aust N Z J Psychiatry 2008;42(5):389-395. DOI: 10.1080/00048670801961115.

104. AlAteeq D, AIDaoud A, AlHadi A, AlKhalaf H, Milev R. The experience and impact of stigma in Saudi people with a mood disorder. Ann Gen Psychiatry 2018;17:51. DOI: 10.1186/s12991-018-0221-3.

105. Mileva VR, Vázquez GH, Milev R. Effects, experiences, and impact of stigma on patients with bipolar disorder. Neuropsychiatr Dis Treat 2013;9:31-40. DOI: 10.2147/NDT.S38560. 
106. Gronholm PC, Henderson C, Deb T, Thornicroft G. Interventions to reduce discrimination and stigma: the state of the art. Soc Psychiatry Psychiatr Epidemiol 2017;52(3):249-258. DOI: 10.1007/s00127-0171341-9.

107. Corrigan P. Beat the Stigma: come out of the closet. Psychiatr Serv 2003;54(10):1313. DOI: 10.1176/appi.ps.54.10.1313.

108. Thornicroft C, Wyllie A, Thornicroft G, Mehta N. Impact of the "Like Minds, Like Mine" anti-stigma and discrimination campaign in New Zealand on anticipated and experienced discrimination. Aust N Z J Psychiatry 2014;48(4):360-370. DOI: 10.1177/0004867413512687.

109. Rüsch N, Angermeyer MC, Corrigan PW. The stigma of mental illness: concepts, forms, and consequences. Psychiatr Prax 2005;32(5): 221-232. DOI: 10.1055/s-2004-834566.

110. Cooke M, Peters E, Fannon D, Anilkumar APP, Aasen I, Kuipers E, et al. Insight, distress and coping styles in schizophrenia. Schizophr Res 2007;94(1-3):12-22. DOI: 10.1016/j.schres.2007.04.030.

111. Hanisch SE, Twomey CD, Szeto ACH, Birner UW, Nowak D, Sabariego $C$. The effectiveness of interventions targeting the stigma of mental illness at the workplace: a systematic review. BMC Psychiatry 2016;16:1. DOI: 10.1186/s12888-015-0706-4.

112. Rai S, Gurung D, Kaiser BN, Sikkema KJ, Dhakal M, Bhardwaj A, et al. A service user co-facilitated intervention to reduce mental illness stigma among primary healthcare workers: utilizing perspectives of family members and caregivers. Fam Syst Health 2018;36(2):198-209. DOI: $10.1037 /$ fsh0000338.

113. Thornicroft G, Mehta N, Clement S, Evans-Lacko S, Doherty M, Rose $D$, et al. Evidence for effective interventions to reduce mental-healthrelated stigma and discrimination. Lancet 2016;387(10023):1123-1132. DOI: 10.1016/S0140-6736(15)00298-6.

114. Griffiths KM, Carron-Arthur B, Parsons A, Reid R. Effectiveness of programs for reducing the stigma associated with mental disorders. A meta-analysis of randomized controlled trials. World Psychiatry 2014;13(2):161-175. DOI: 10.1002/wps.20129.

115. Büchter RB, Messer M. Interventions for reducing self-stigma in people with mental illnesses: a systematic review of randomized controlled trials. Ger Med Sci 2017;15:Doc07. DOI: 10.3205/000248. 